be a valuable learning experience for the participants and the facilitators.

Method We surveyed the Foundation doctors asking them how much leadership teaching they had previous had and to rank their confidence in their leadership abilities, how keen they were to develop and improve their leadership skills and whether leadership teaching is important and relevant for them as Foundation doctors. We arranged a peer led leadership teaching session for foundation doctors which consisted of several short workshops. These were 'difficult conversations', 'followership', 'resilience and how to develop in your team' and a 'senior doctors experience'. We then assessed whether it was an effective way to improve understanding and engagement in leadership by repeating the survey asking the same three questions. The Results were analysed using a two tailed paired T-test $(\mathrm{n}=23, \mathrm{p}<0.05)$.

Results Feedback from the facilitators and participants was positive. The mean rating by the participants was $4.4 / 5$. Most trainees had received very little or no formal leadership teaching prior to the session (median $=0$ ). The teaching session showed an improvement in all 3 areas assessed, notably in the confidence of participants in their leadership ability, increasing from $3.3 / 5$ to $3.5 / 5$ ( $\mathrm{p}<0.05$ ).

Conclusion Our research illustrates the lack of formal leadership teaching for foundation doctors. This project demonstrates that peer to peer teaching is an effective way to help build confidence and understanding both for those who receive the session and those who organise it. We hope that our leadership teaching model will be replicated across other foundation schools in the UK.

\section{REFLECTIONS AND LESSONS FROM ORGANISING THE INAUGURAL SOUTH WEST LEADERSHIP CONFERENCE: NEXT GENERATION LEADERS}

\begin{abstract}
${ }^{1}$ Sophie McGlade*, 'Ben Ballisat, 'Samantha Cockburn, 'Mark Eveleigh, 'Carla Fleming, ${ }^{1}$ Sam Hayward, ${ }^{1}$ Freya Smith-Jack, ${ }^{2}$ Elliott Haines, ${ }^{2}$ Rachel Homer, ${ }^{3}$ Jane Thurlow. ${ }^{1}$ Health Education England South West Leadership Fellow, UK; ${ }^{2}$ Torbay and South Devon NHS Foundation Trust, UK; ${ }^{3}$ Health Education England South West, UK
\end{abstract}

\subsection{6/leader-2019-FMLM.7}

Introduction The inaugural South West leadership conference, 'Next Generation Leaders', was held in March 2019. This was open to 200 trainees and was jointly organised by the seven Health Education England South West (HEE-SW) Leadership Fellows and two Academic Foundation doctors. It was funded by HEE-SW through the Severn deanery in collaboration with the Leadership Academy.

Issue The importance of good leadership skills in junior doctors is increasingly recognised; this conference aimed to inspire and equip clinicians with leadership skills. Topics included exploring leadership during challenging circumstances, leadership development, human factors and organisational structures.

We adopted a distributive leadership approach, rapidly learning how to organise and promote a conference in budget, inviting speakers, providing network opportunities, website design and coordinating poster presentations.

Intervention The conference delivered a varied programme with full details available at the event website (www.nextgenerationleaders.net). A diverse range of speakers were invited from within healthcare and other industries. We aimed for total inclusivity for all trainees across the South West, being free to access, central location and flexible content.

Measurement Feedback from delegates was obtained via an electronic survey. Analysis showed the conference was well received, 98\% of attendees recommended the conference.

Lessons Reflections of the organising committee centred around how we worked as a team, bonding at the start of the fellowship and becoming a cohesive group.

Through our individual and collective experiences this conference has acted as a catalyst to furthering our own leadership development inspiring us to pursue future opportunities.

We would like to inform and inspire others interested in organising similar events. We hope to promote others to seek out leadership development opportunities, which is crucial for the future of the NHS.

\section{THE CHALLENGE OF ACCESS: A LITERATURE REVIEW OF 'IMPACT' IN RELATION TO THE EFFORTS OF WIDENING PARTICIPATION INTO MEDICINE}

ES Adeeko, ER Reid. Warwick Medical School, University of Warwick, UK

\subsection{6/leader-2019-FMLM.8}

Background and aims Widening Participation (WP) and Widening Access (WA) endeavours to widen opportunities for students from disadvantaged backgrounds. This holds significance within medicine considering the diversifying patient-population, that is not yet reflected within the practicing-workforce or student-population. Despite increased efforts towards improving this, there is limited evidence-based knowledge as to how much of an effect this work is having. Our review further explores this.

Methods A critical literature review was conducted via an online search-strategy of eight educational databases, one medical database and use of grey literature.

Results On analysis, it became clear there was a multifactorial foundation to this issue. The use of terminology with inconsistent definitions, even between well-established institutions, has led to ambiguity and interchangeable use of the terms WA and WP. This is despite WA being a singular division of the WP initiative. Another aspect lies in the discrepancy of efforts towards known WP barriers. This has led to skewed interpretation of WP intervention and disproportionate focus on the issue of socioeconomic status, discounting other barriers such as ethnicity, disability and gender. There is also insufficient research into the results of WP past the point of medical school.

Conclusion Despite substantial contact, there is a lack of evidence supporting positive long-term effects. Most likely due to misalignment of core ideals constituting WP and WA, along with limited literature availability, there becomes insufficient grounds to express more than minimal impact produced by WP in medicine. WP is of critical importance to the medical sector not only in education but also practice, and as such the leading voices in medicine need to be aware of its current state. This would fundamentally serve the health of future populations, enabling a wider populace to not only enter medicine but participate and flourish within it. 